\title{
An Analysis of Coordinate Changes of the Permanent Geodetic Stations KRAW and KRA1 During the Flood in 2010**
}

\section{Introduction}

In the middle of 2010 on Polish territory occurred a flood, in consequence large areas along the Vistula and Odra River were flooded. This flood was one of the largest recorded so far. The water level in the Vistula River in many locations exceeded the level of the flood in 1997. Also, in Cracow in the second half of May and the beginning of June a very high state of the Vistula River level was recorded. After passing the first wave of the flood in mid-May's, in result of return intense rainfall in early June the water level again overran alarm states in the upper basin of the Vistula and Odra River.

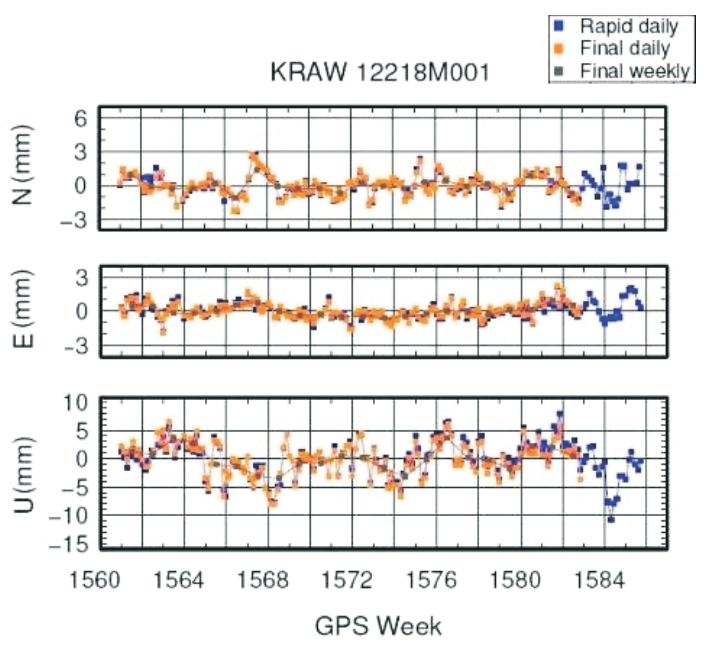

Fig. 1. 1-day coordinates solutions of KRAW station (LAC - WUT) [1]

* AGH University of Science and Technology, Faculty of Mining Surveying and Environmental Engineering, Department of Geomatics, Krakow, Poland

** This work has been made with Dean's Grant no. 15.11.150.131 
During the passage of the first wave peak through Cracow (1584 GPS Week) the Local Analysis Center at Warsaw University of Technology (LAC WUT) detected a reduction of ellipsoid height of permanent stations. It was based on studies of daily measurements of GPS signals at KRA1 and KRAW stations, located on building C-4 (Faculty of Mining Surveying and Environmental Engineering) of AGH-UST in Cracow (Fig. 1) [1].

Higher status of water surface determines a change in levels of groundwater and causes additional loading of the crust [3]. These factors may affect a change of permanent GPS station coordinates, located near the flood wave. This paper presents the results of the analysis of several permanent GPS stations in order to determine the possible impact of the flood changes on their coordinates.

\section{Groundwater and Surface Water}

Groundwater level is measured in relation to surface level, thus increasing the groundwater level makes the depth decrease, while the falling - increases. The relationship between the river water level and groundwater level depends on several factors. This is determined mainly by conditions of depth of aquifer, outflow places of groundwater in relation with river water level and depth of indentation of river valleys [2]. Long rainless periods may supply rivers with groundwater [4]. However, in the case of exceeding the river water levels above groundwater level occurs the filtration of river water into the coastal zone. The width of the coastal zone, where the influence of the river to groundwater is visible, depends on the period when states remain high, and the slope of the groundwater level remains.
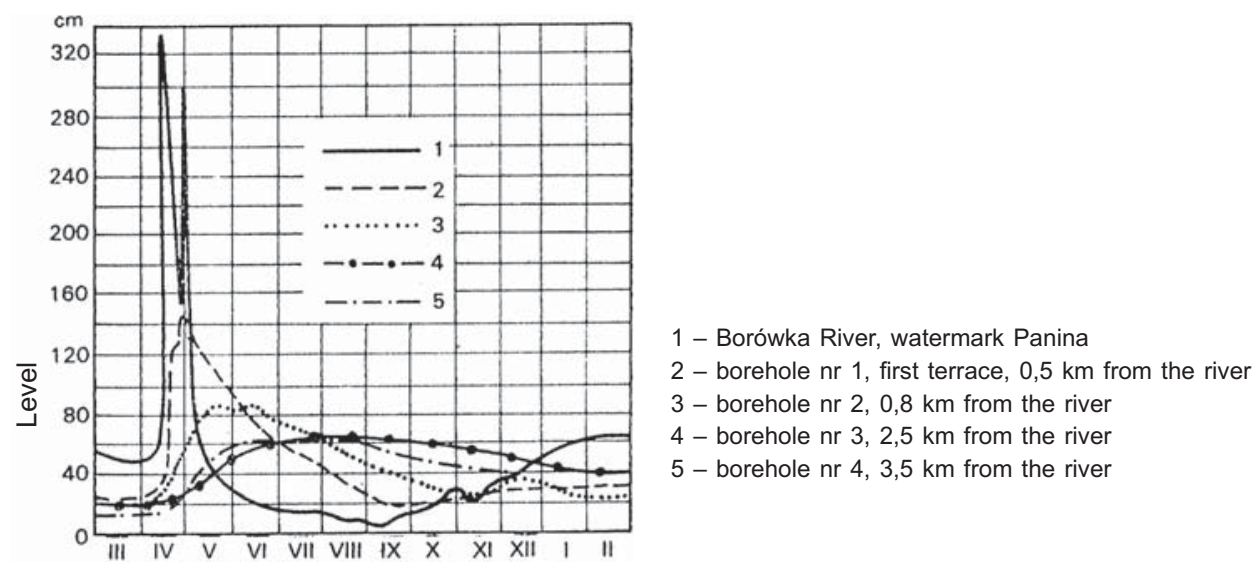

Fig. 2. Fluctuations of Borówka's river (Poland) level and groundwater level presented in various distances from river [2] 
The greater the distance from the stream channel, the smaller the impact of the river on the groundwater level and in time becomes invisible or may proceed independently of the river's level (Fig. 2) [2].

Table 1 gives the distances between permanent stations and the Vistula River (col. 2), time intervals which information about the state of the Vistula River's surface level was collected ${ }^{1}$ (col. 3) and data about groundwater level ${ }^{2}$ (col. 4) from piezometer located on the square between buildings A3-A4 at AGH University of Science and Technology (Fig. 3). In addition, column 5 shows differences between the maximum and minimum value of watermark indications in analyzed time $\left(\Delta p=p_{\max }-p_{\min }\right)$.

Table 1. Collected data at individual station

\begin{tabular}{|c|c|c|c|c|}
\hline \multirow[b]{2}{*}{ Station } & \multirow[b]{2}{*}{$d[\mathrm{~m}]$} & Watermark & Piezometer & \multirow[b]{2}{*}{$\Delta p[\mathrm{~cm}]$} \\
\hline & & \multicolumn{2}{|c|}{$\begin{array}{l}\text { collected data } \\
\text { [GPS Week] }\end{array}$} & \\
\hline 1 & 2 & 3 & 4 & 5 \\
\hline CBKA & 250 & 1583-1586 & - & 544 \\
\hline KRAW & 1370 & 1583-1586 & 1579-1592 & 712 \\
\hline WLOC & 510 & 1583-1585 & - & 534 \\
\hline
\end{tabular}

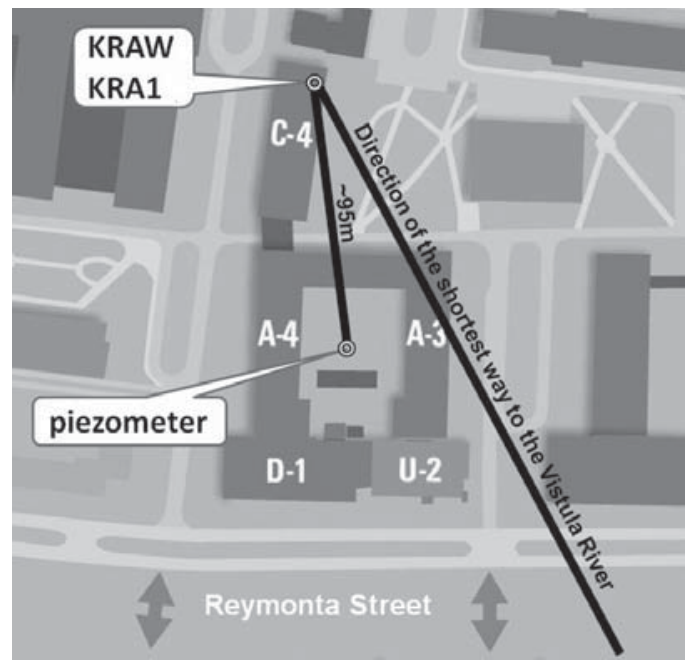

Fig. 3. Location of KRAW and KRA1 stations and piezometer relative to the Vistula River

1 Data from pogodynka.pl (weather service of Institute of Meteorology and Water Management).

2 Data obtained from Department of Hydrogeology and Engineering Geology, Faculty of Geology, Geophysics and Environment Protection AGH-UST. 


\section{Development of GPS Observations}

There were analyzed daily graphs of changes of EUREF's geodetic permanent reference stations between 21 March and 11 September of 2010 (1576-1600 GPS week) (Fig. 4).

These are daily solutions (final daily) obtained by Local Analysis Centers (LAC):

- BKG - Bundesamt für Kartographie und Geodäsie, Frankfurt, Germany;

- MUT - Military University of Technology, Warsaw, Poland;

- OLG - Institute for Space Research (ISR/ASS), Graz, Austria;

- SGO - FOMI Satellite Geodetic Observatory, Budapest, Hungary;

- SUT - Slovak University of Technology, Bratislava, Slovakia;

- WUT - Warsaw University of Technology, Poland.

Moreover, in figure 4 were plotted 3-day, moving average including data presented on each graph (black color, plot "m3d"). On these graphs also passage of the wave peak by Cracow: the first one on 19 May 2010 (GPS week.DOW: 1584.3) and the second one on 4 July (1586.5) were marked out by two vertical lines date. On the KRA1 and KRAW stations a sharp reduction of station height can be seen during the passage of two successive wave peaks through Cracow. This effect is not seen on the WROC (Wrocław) station. A result of the reduction of heights of KRAW and KRA1 stations is showed apparently in figure 5, where more precise graphs of ellipsoidal heights during the passage of the wave peak presented, adding also three graphs for the KATO (Katowice), ZYWI (Żywiec) and GANP (Ganovce, Slovakia) stations. On the graphs presenting the KATO and ZYWI stations it is noted similar, like on the two Cracow stations, reduction of ellipsoidal heights. An amplitude of reduction of height element during the passage of the wave peak is about $4-5$ millimeters for each of analyzed stations for the first wave, and about $2-3 \mathrm{~mm}$ for the second. Also, it should be noted that during the analyzed period there was the same or even larger amplitude of changes in height, which has accidental nature.

In the next step of research there were analyzed observations from three ASG-EUPOS network stations, which are located a short distance from the Vistula River. An effect of the flood wave geodetic coordinates was analyzed on three reference stations: KRAW (University of Science and Technology, Cracow), CBKA (Space Research Centre, Polish Academy of Sciences, Warsaw), WLOC (Provincial Center of Geodetic and Cartographic Documentation, Włocławek). Chosen stations were located at a distance from $250 \mathrm{~m}$ to $1370 \mathrm{~m}$ from the Vistula River (Tab. 1). 


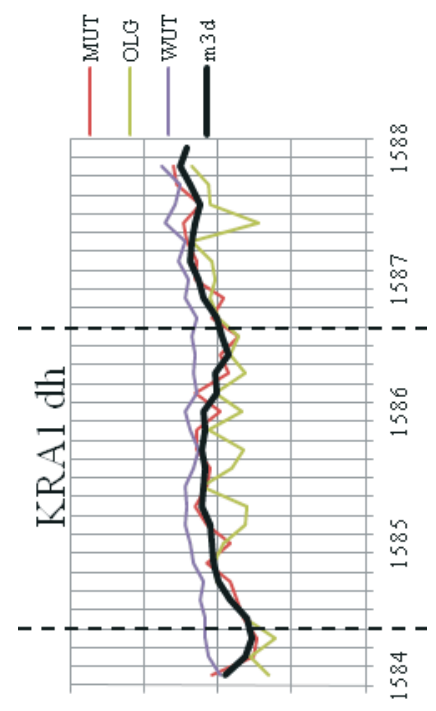

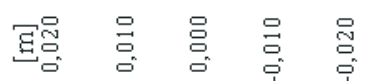

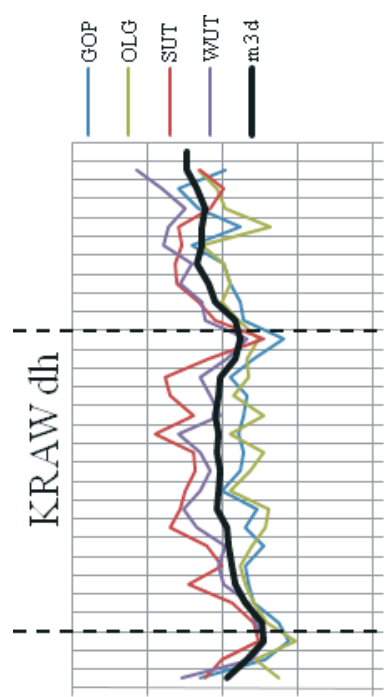

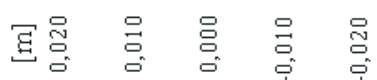

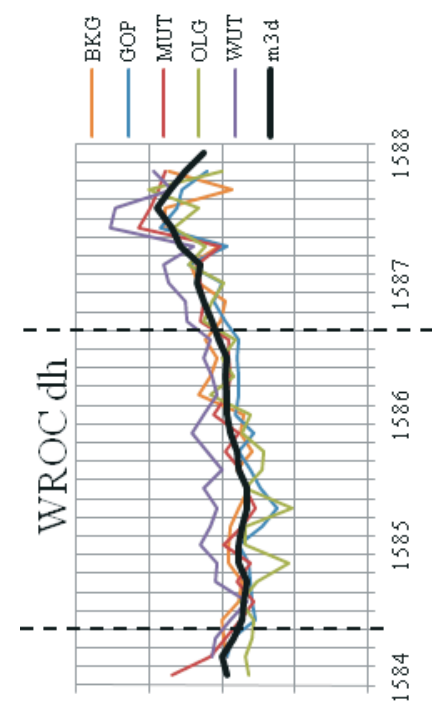

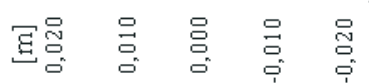

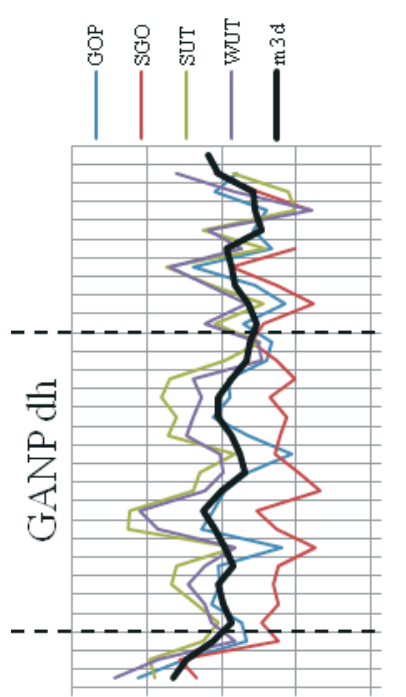

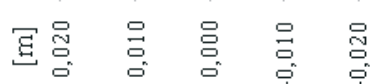

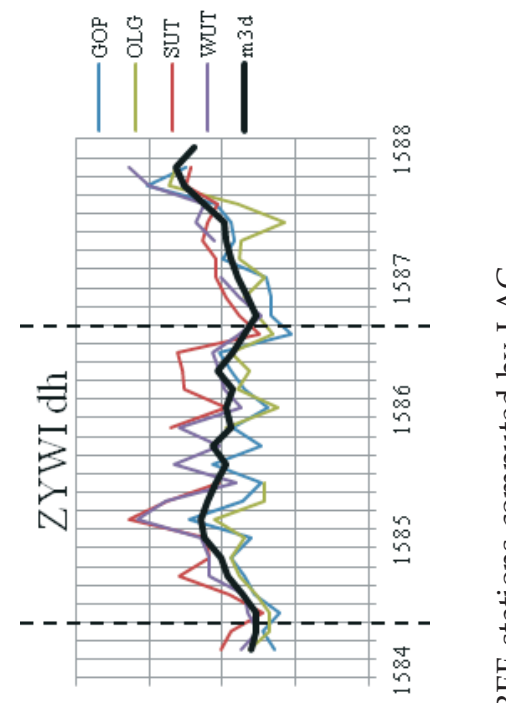

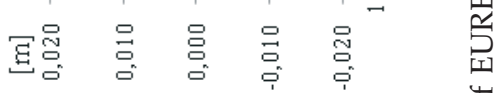

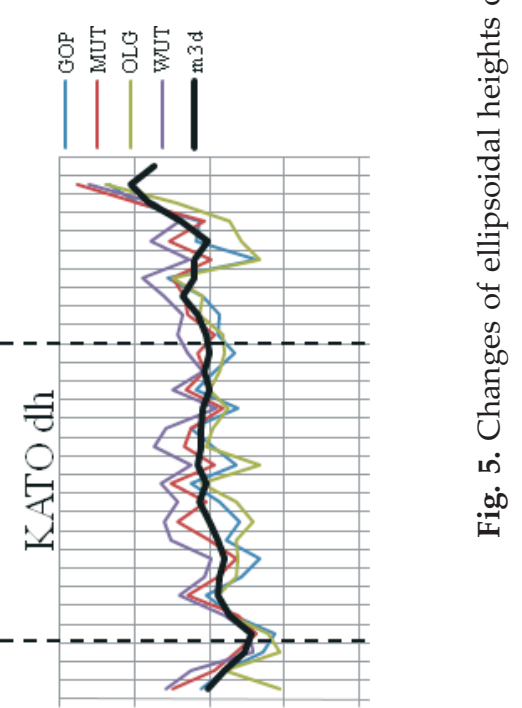

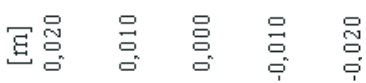

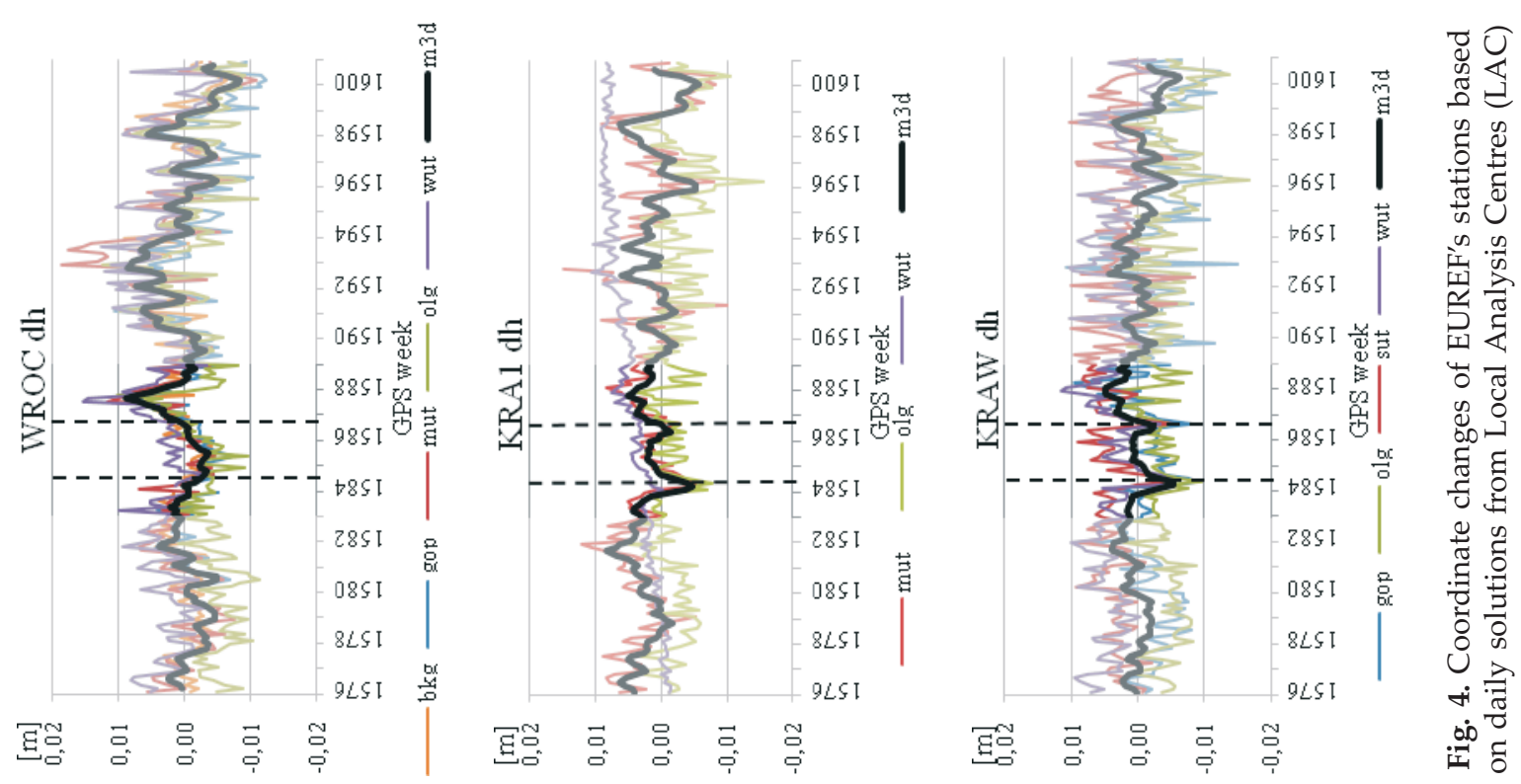


8 water level [cm]

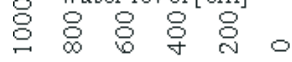

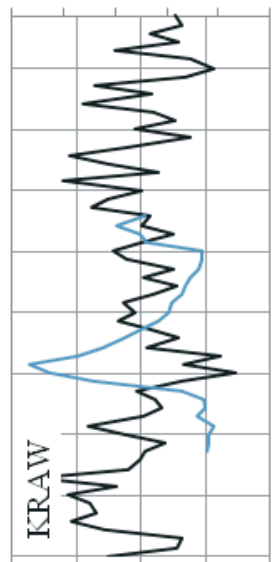

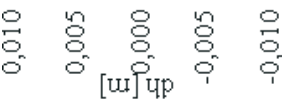

water level [cm]

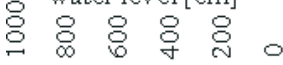

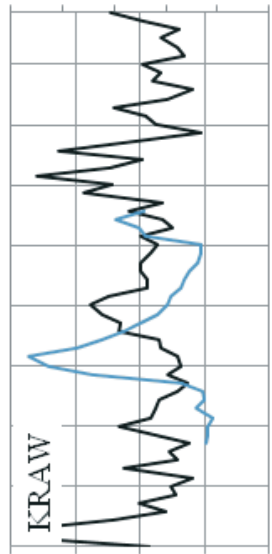

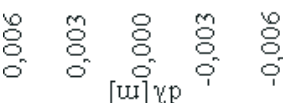

- water level [cm]

88888

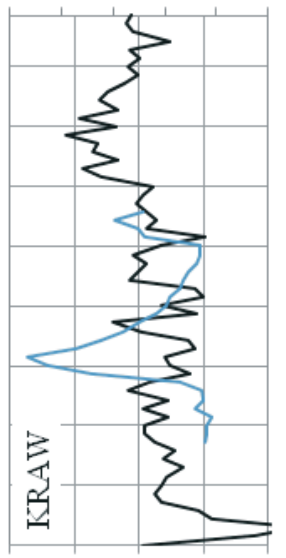

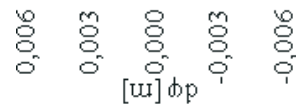

8 water level $[\mathrm{cm}]$

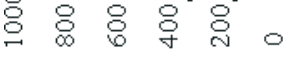

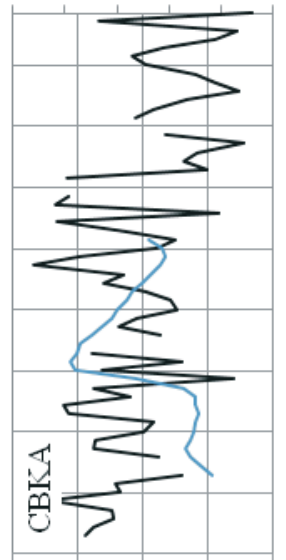

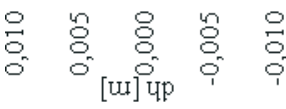

water level [cm]

品品吕学总。

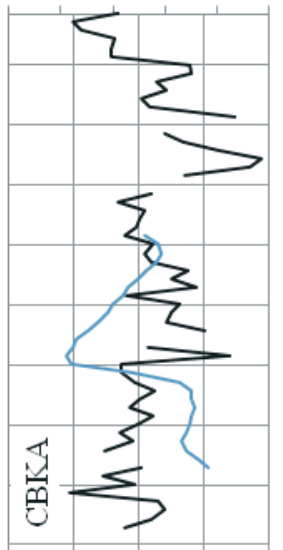

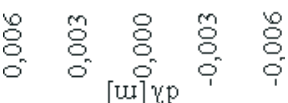

water level [cm]

总品吕学总。

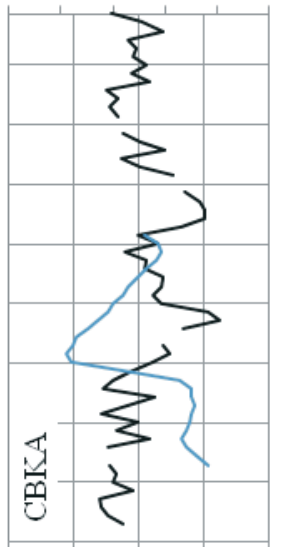

응

[u] dp water level [cm]

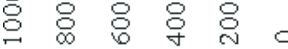

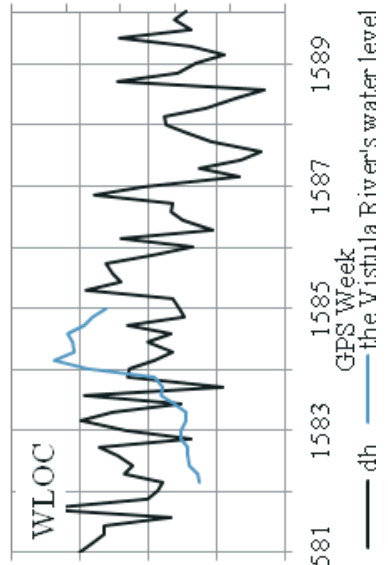

政

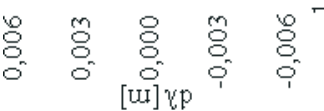

8 water level [cm]

\& 8 \& 8 \&

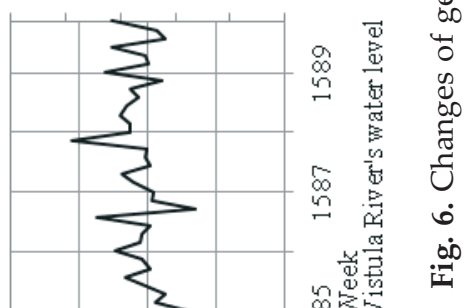

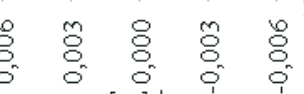

[u]dp 
As reference points were selected EPN stations, lying outside of the Polish borders, and thus not affected by the flooding. These were stations: BUCU (Bucharest, Romania), GLSV (Kiev, Ukraine), POTS (Potsdam, Germany), VIS0 (Visby, Sweden). Their coordinates in a solution were taken as fixed. Daily observations were analyzed from 1 May to 5 July of 2010 in 30-second intervals.

There were used the files containing at least 2760 epochs of observation per day (min. 23 hours). In the development of GPS measurements satellites with more than $3^{\circ}$ of elevation mask were taken into consideration. The observations were made by receivers Ashtech UZ-12 (CBKA, KRAW) equipped with antennas ASH701945E_M (CBKA) without cover and ASH701945C_M with cover type SNOW (KRAW). At the WLOC station, Trimble NetRS was a receiver, with antenna TRM41249.00 with TZGD type of cover. All stations of the ASG-EUPOS network were located on the roofs of the buildings.

The observations of the GPS signals were developed using Bernese GPS Software 5.0 [6]. Calculated coordinates in ITRF2005 reference frame at observation epoch, were transformed to epoch 2005.0. Troposphere refraction includes using a Dry Neill model with a 2-hour measuring interval [5]. Ionosphere correction includes using a global ionosphere model of CODE Analysis Center. Phase ambiguities were calculated using a combination of L1 and L2 frequencies called Quasi Ionosphere Free (QIF). MAX-OBS (maximum number of carrier phase single differences) was a baselines strategy selection.

Figure 6 shows calculated changes of the coordinates of analyzed stations in relation to changes of the Vistula River's level. In the KRAW station ellipsoidal height of analyzed stations a relationship, like as in figure 4 and 5, can be seen. It was not noticed at the CBKA and WLOC stations. A calculated correlation coefficient between changes in the KRAW's ellipsoidal height and fluctuation in the Vistula River's water level has a negative relationship value $(-0.65)$. Reduction of the KRAW's ellipsoidal height at the moment of culmination of the first wave is about $6-7 \mathrm{~mm}$. This phenomenon is less evident in the second wave, where the amplitude amounts to only $2 \mathrm{~mm}$. The large data scatter around the mean value, indicative of worse quality than the data from Local Analysis Centers is noted.

Figure 7a shows changes in groundwater level near the KRAW station, calculated ellipsoidal height and its moving average ("m3d"). A calculated correlation coefficient between the groundwater level and the Vistula River's surface water level is 0.57 . However, the correlation coefficient between the ellipsoidal height and the groundwater level is -0.19 . This follows from change of the rise of groundwater level relative to water level changes on the Vistula River at the time, due to the large distance separating them (Fig. $7 b$ ). However, the speed of increasing water level in piezometer on this distance (over $1 \mathrm{~km}$ ) can be explained by pressure reaction. 

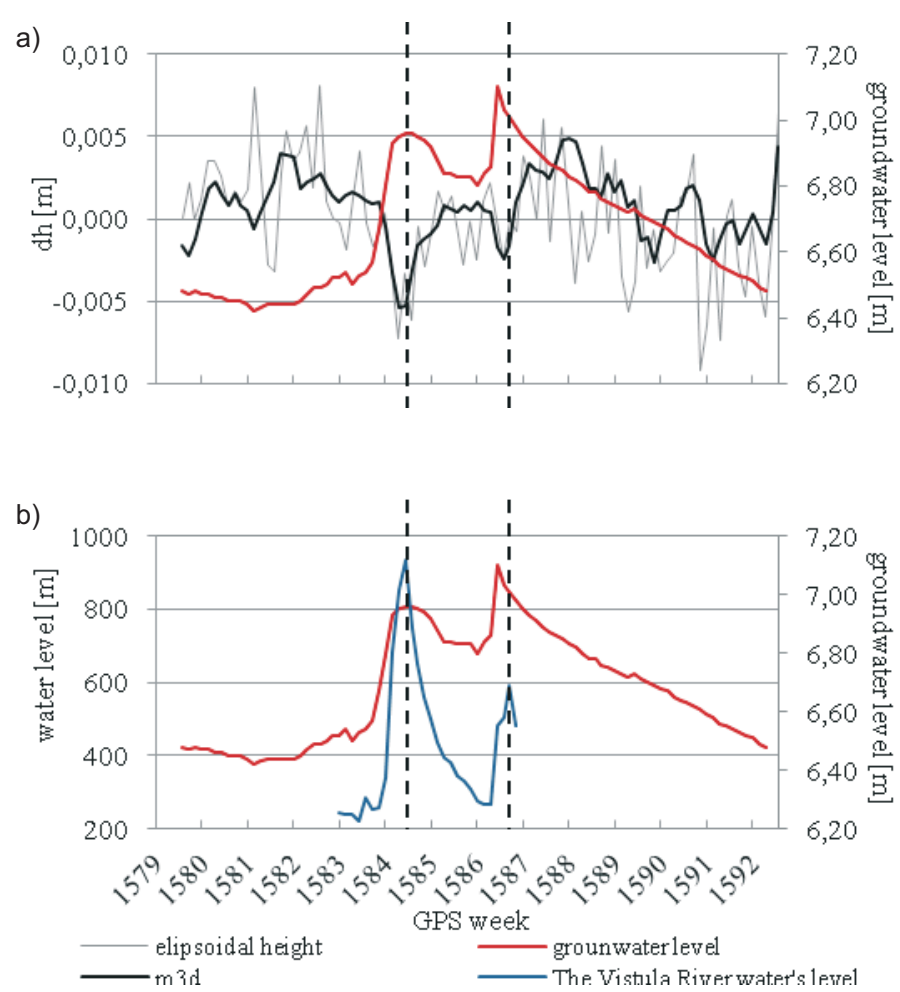

Fig. 7. Correlation of changes of groundwater level and surface water level with KRAW's ellipsoidal height changes

\section{Conclusions}

The aim of this study is a determination of the flood's impact on selected reference stations. Change in station height during the passage of the flood wave was seen only at stations located in southern Poland. Despite a marked decrease of the building where the stations KRAW and KRA1 are located, it is difficult to justify the impact of the flood because of a similar change at KATO and ZYWI stations. In order to relate the changes in permanent GPS station coordinates with fluctuations in river level it is necessary to combine classic measurements of leveling on section river-permanent station buildings using GPS station measurements. In 2011 at the Faculty of Mining Surveying and Environmental Engineering is intended to set such a section of leveling and a periodic study of changing benchmark heights during high levels of the Vistula River's water by satellite and classical methods. 


\section{References}

[1] Liwosz T., Kruczyk M., Rogowski J.: Prace badawcze Lokalnego Centrum Analiz EUREF przy Politechnice Warszawskiej. Symposium „Współczesne problemy osnów podstawowych", Grybów 2010.

[2] Dawydow L.K., Dmitrijewa A.A., Konkina N.G.: Hydrologia ogólna. Warszawa 1979.

[3] Pleczyński J.: Odnawialność zasobów wód podziemnych. Warszawa 1981.

[4] Atlas hydrologiczny Polski. T. 2. Wydawnictwa Geologiczne, Warszawa 1986.

[5] Niell A.E.: Global Mapping Functions for the Atmosphere Delay at Radio Wavelengths. Journal of Geophysical Research, vol. 101(B2), 1996, pp. 3227-3246.

[6] Bernese GPS Software Version 5.0. Astronomical Institute, University of Bern, 2007. 